Original Article

\title{
Effect of visual stimulus using central and peripheral visual field on postural control of normal subjects
}

\author{
Du-Jin PARK, PhD, $\mathrm{PT}^{1)}$ \\ 1) Department of Physical Therapy, College of Health Medicine, Kaya University: 208 Samgye-ro, \\ Gimhae, Kyongnam 609-757, Republic of Korea
}

\begin{abstract}
Purpose] This study investigated the effects of visual stimulus using central and peripheral vision fields on postural control. [Subjects and Methods] The subjects consisted of 40 young adult volunteers (15 males, 25 females) who had been informed of the study purpose and procedure. The subjects were randomly divided into four groups of differing visual stimulus. Each group was given visual intervention in a standing position for 3 minutes. Postural control was evaluated before and after visual intervention. [Results] The results of the functional reach test and body sway test showed significant differences among the four groups. [Conclusion] The two-way peripheral vision-field group showed significantly more body sway after visual intervention than the other three groups. This finding may suggest two-way peripheral vision field is a more effective visual stimulus for training postural control and balance.

Key words: Central vision field, Peripheral vision field, Postural control
\end{abstract}

(This article was submitted Jan. 19, 2016, and was accepted Feb. 28, 2016)

\section{INTRODUCTION}

Postural instability is associated with insufficient movement ${ }^{1)}$ as well as falling ${ }^{2)}$. To address these problems, it is necessary to improve postural control. Postural control is a complex task based on the integration of visual, vestibular and proprioceptive information ${ }^{3)}$. Visual information of afferent information plays an important role in postural control. This contributes to anticipatory postural control, providing information about the difficulty of an activity as well as the body position ${ }^{4}$. Although postural control can be influenced by any of the three sensory systems, the visual system can reduce postural disturbance by as much as $50 \%{ }^{5)}$.

Human vision can be divided into the central vision field (CVF) and peripheral vision field (PVF) ${ }^{6}$. CVF refers to the central point at which the pupils are directed, whereas PVF is a visual field formed outside of CVF. Vection is the visuallyinduced illusion of self-motion while actually stationary, and it is often triggered by movement of a large part of the visual field $^{7}$. Vection can be triggered by stimulation within the CVF and PVF, both of which affect postural control. Although various training programs have been conducted for postural control in the clinical field, few studies have investigated the effects of postural control training using CVF and PVF stimulation. Therefore, this study investigated the effects of CVF and PVF visual stimuli on postural control.

\section{SUBJECTS AND METHODS}

The study subjects were 40 young adult volunteers ( 15 males, 25 females) who were informed of the study purpose and procedure. The average age, height, weight and BMI of the subjects were $21.53 \pm 2.34$ years, $166.25 \pm 7.30 \mathrm{~cm}, 58.83 \pm$

Corresponding author. Du-Jin Park (E-mail: djpark35@kaya.ac.kr)

(C2016 The Society of Physical Therapy Science. Published by IPEC Inc.

This is an open-access article distributed under the terms of the Creative Commons Attribution Non-Commercial No Derivatives (by-nc-nd) License $<$ http://creativecommons.org/licenses/by-nc-nd/4.0/>. 
$11.37 \mathrm{~kg}, 21.21 \pm 3.33 \mathrm{~kg} / \mathrm{m}^{2}$, respectively. The participants were randomly assigned to one of four groups (CVF1, CVF2, PVF1, PVF2). The CVF1 and CVF2 groups were respectively presented with one-way and two-way vertical straight patterns as CVF stimulus. The PVF1 and PVF2 groups were respectively presented with one-way and two-way vertical straight patterns as PVF stimulus. This study excluded individuals with diseases related to visual disorder or problems of postural control, and those taking medicine for balance adjustment. The approval of the Ethics Committee of Kaya University was obtained prior to beginning data collection.

In this study, visual intervention consisted of a vertical straight pattern, based on the results of a previous study ${ }^{8)}$ in which the vertical straight pattern was reported to be more effective for balance training than the other patterns. Additionally, the present study employed one- and two-way patterns (Fig. 1). For intervention consistency, the subjects were instructed to look at the central point of an image ${ }^{7)}$. The visual intervention lasted 3 minutes.

To examine the effects of the visual intervention on postural control, the subjects performed the one leg standing test (OLST), functional reach test (FRT) and body sway test (BST) before and after the intervention. OLST was performed with closed eyes on the dominant leg. The maximum duration of OLST was 30 seconds. After all subjects had one practice attempt, FRT was performed to identify dynamic balance ability. Body sway was measured using a BIORescue device (RM Ingénierie, Rodez, France). Evaluations were performed before and after the visual intervention.

ANOVA was conducted to examine the effect of visual stimulus, CVF and PVF, on postural control. Tukey's multiple comparison test was used for post hoc analysis. SPSS (version 18.0 for Windows, Chicago, IL, USA) was used for statistical analysis, with a significance level of $\alpha=0.05$.

\section{RESULTS}

There were no significant differences in the general characteristics among the four groups. FRT and BST showed significant differences among the four groups (Table 1). The results of post hoc analysis of the differences in FRT showed there were significant differences between CVF1 and CVF2, and CVF1 and PVF2. BST was significantly different between CVF1 and PVF1, CVF1 and PVF1, CVF1 and PVF2, and PVF1 and PVF2.

\section{DISCUSSION}

The retina contains Y-cells and X-cells. The Y-cells allow sensitive motion-detection and play a key role in PVF ${ }^{9)}$. A previous study reported that PVF plays a more dominant role in self-motion cognition than CVF ${ }^{10)}$. However, the results of FRT showed significant differences between CVF1 and CVF2, and between CVF1 and PVF2. This is attributable to the influence of two-way visual stimulus. In a previous study ${ }^{8)}$, subjects only received one-way stimulus, whereas the present study utilized one-way or two-way visual stimuli. In the present study, FRT was more greatly influenced by the two-way stimulus than by the one-way visual stimulus.

The BST results differed significantly between CVF1 and PVF1. This supports the findings of previous studies ${ }^{8,10)}$, which showed that PVF plays a dominant role in self-motion cognition and has a greater influence than CVF on postural control.

Additionally, PVF2 was found to generate significantly more body sway after visual intervention than the stimuli of the other groups. This finding may suggest that PVF with a two-way pattern (PVF2) is a more effective visual stimulus for postural control and balance training. Previous studies have reported that visual training may be effective for postural

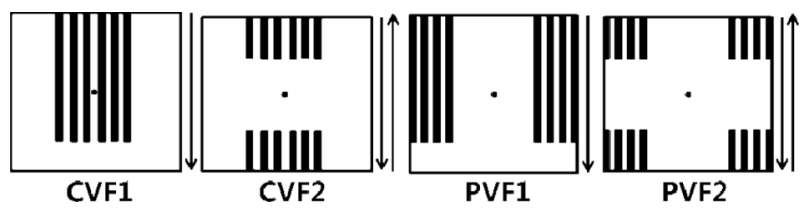

Fig. 1. Visual interventions using the central and peripheral vision field

Table 1. Changes in balance abilities elicited by different visual stimuli

\begin{tabular}{lcccc}
\hline & CVF 1 & CVF 2 & PVF 1 & PVF 2 \\
\hline OLST (sec) & $-1.67 \pm 5.39$ & $-2.67 \pm 5.25$ & $-3.04 \pm 4.02$ & $-4.42 \pm 3.75$ \\
FRT (cm) & $-2.93 \pm 3.09^{\mathrm{a}}$ & $-6.43 \pm 3.24^{\mathrm{b}}$ & $-4.80 \pm 2.40^{\mathrm{ab}}$ & $-6.87 \pm 2.70^{\mathrm{b}}$ \\
BST (mm) & $61.50 \pm 53.41^{\mathrm{a}}$ & $96.23 \pm 73.71^{\mathrm{ab}}$ & $121.31 \pm 36.22^{\mathrm{b}}$ & $177.00 \pm 20.92^{\mathrm{c}}$ \\
\hline a, b, c Values within a row with different superscripts are significantly different (p<0.05); OLST: one leg standing \\
test; FRT: functional reach test; BST: body sway test; CVF: central vision field; PVF: peripheral vision field
\end{tabular}


and balance training of people with stroke ${ }^{11,12)}$. Therefore, PVF with a two-way pattern (PVF2) would be appropriate for neurological patients, as well as athletes who require highly developed balance. The present study focused on identifying the immediate effects of visual intervention. In future studies, it will be necessary to verify the long-term effects of PVF with a two-way pattern (PVF2) on the postural control of neurological patients and athletes.

In Korea, many neurological rehabilitation environments include the use of mirrors. However, PVF stimulus via surrounding mirrors can frustrate attempts to correct patients' balance problems. Future research is necessary to examine the effects of using mirrors in postural control programs to correct the balance problems of neurological patients.

\section{REFERENCES}

1) Isaacs B: Clinical and laboratory studies of falls in old people. Prospects for prevention. Clin Geriatr Med, 1985, 1: 513-524. [Medline]

2) Turano K, Rubin GS, Herdman SJ, et al.: Visual stabilization of posture in the elderly: fallers vs. nonfallers. Optom Vis Sci, 1994, 71: 761-769. [Medline] [CrossRef]

3) Rougier P, Farenc I, Berger L: Modifying the gain of the visual feedback affects undisturbed upright stance control. Clin Biomech (Bristol, Avon), 2004, 19: 858-867. [Medline] [CrossRef]

4) Lee HS, Choi HS, Kwon OY: A literature review on balance control factors. KAUTPT, 1996, 3: 82-91.

5) Edwards AS: Body sway and vision. J Exp Psychol, 1946, 36: 526-535. [Medline] [CrossRef]

6) Straube A, Krafczyk S, Paulus W, et al.: Dependence of visual stabilization of postural sway on the cortical magnification factor of restricted visual fields. Exp Brain Res, 1994, 99: 501-506. [Medline] [CrossRef]

7) Kawakita T, Kuno S, Miyake Y, et al.: Body sway induced by depth linear vection in reference to central and peripheral visual field. Jpn J Physiol, 2000, 50: 315-321. [Medline] [CrossRef]

8) Kim HS, Kim DW, Cha EJ, et al.: Human postural balance control by visual stimulation. J KOSOMBE, 1996, 17: 417-425.

9) Gu J, Kim YM, Park JW, et al.: Visual effects for augmented reality in home theater environments. HCI Korea, 2005 , 1: 612-616.

10) Brandt T, Dichgans J, Koenig E: Differential effects of central verses peripheral vision on egocentric and exocentric motion perception. Exp Brain Res, 1973, 16: 476-491. [Medline] [CrossRef]

11) Lee SW, Shin DC, Song CH: The effects of visual feedback training on sitting balance ability and visual perception of patients with chronic stroke. J Phys Ther Sci, 2013, 25: 635-639. [Medline] [CrossRef]

12) Ko Y, Ha H, Bae YH, et al.: Effect of space balance 3D training using visual feedback on balance and mobility in acute stroke patients. J Phys Ther Sci, 2015, 27: 1593-1596. [Medline] [CrossRef] 